\title{
Solution structure of an intramolecular (3+1) human telomeric G- quadruplex bound to a telomestatin derivative
}

\author{
Wan Jun Chung ${ }^{1 \dagger}$, Brahim Heddi ${ }^{1} \pitchfork$, Masayuki Tera ${ }^{2}$, Keisuke Iida ${ }^{2}$, \\ Kazuo Nagasawa ${ }^{2}$, and Anh Tuân Phan,"*
}

\footnotetext{
${ }^{1}$ School of Physical and Mathematical Sciences, Nanyang Technological University, Singapore and ${ }^{2}$ Department of Biotechnology and Life Science, Faculty of Technology, Tokyo University of Agriculture and Technology, Japan
}

Supporting Information 
Table S1. Site-specific labeled $H T$ used in this study; $4 \%-{ }^{13} \mathrm{C},{ }^{15} \mathrm{~N}$-labeled thymines are marked by asterisks; ${ }^{2} \mathrm{H}$-labeled guanines and adenines at the $\mathrm{H} 8$ position are marked by hash sign.

\begin{tabular}{|c|c|c|c|c|c|c|c|c|c|c|}
\hline Type & \multicolumn{9}{|c|}{ Sequence (5'-3') } & Name \\
\hline \multirow[t]{6}{*}{${ }^{2} \mathbf{H}$-labeled } & TT & ${ }^{\#}$ GGG & TTA & GGG & TTA & GGG & TTA & GGG & $\mathrm{A}$ & \multirow[t]{12}{*}{$H T$} \\
\hline & TT & GGG & $\mathrm{TT}^{\#} \mathrm{~A}$ & GGG & TTA & GGG & TTA & GGG & A & \\
\hline & TT & GGG & TTA & $\mathrm{G}^{\#} \mathrm{GG}$ & TTA & GGG & TTA & GGG & A & \\
\hline & TT & GGG & TTA & GGG & $\mathrm{T}^{\#} \mathrm{~A}$ & GGG & TTA & GGG & A & \\
\hline & TT & GGG & TTA & GGG & TTA & GGG & $\mathrm{TT}^{\#} \mathrm{~A}$ & GGG & A & \\
\hline & $\mathrm{TT}$ & GGG & TTA & GGG & TTA & GGG & TTA & $\mathrm{G}^{\#} \mathrm{GG}$ & A & \\
\hline \multirow[t]{6}{*}{${ }^{13} C^{, 15} \mathrm{~N}$-labeled } & $\mathrm{T} * \mathrm{~T}$ & GGG & TTA & GGG & TTA & GGG & TTA & GGG & A & \\
\hline & TT & GGG & *TTA & GGG & TTA & GGG & TTA & GGG & A & \\
\hline & TT & GGG & $\mathrm{T} * \mathrm{TA}$ & GGG & TTA & GGG & TTA & GGG & A & \\
\hline & TT & GGG & TTA & GGG & *TTA & GGG & TTA & GGG & A & \\
\hline & TT & GGG & TTA & GGG & TTA & GGG & *TTA & GGG & A & \\
\hline & TT & GGG & TTA & GGG & TTA & GGG & $\mathrm{T} * \mathrm{TA}$ & GGG & A & \\
\hline
\end{tabular}


Table S2. Human telomeric G-quadruplexes with their corresponding name and sequence.

\begin{tabular}{|c|c|c|c|c|c|c|c|c|c|}
\hline \multicolumn{9}{|c|}{ Sequence $\left(5^{\prime}-3^{\prime}\right)$} & \multirow{2}{*}{$\begin{array}{l}\text { Name } \\
H T\end{array}$} \\
\hline TT & GGG & TTA & GGG & TTA & GGG & TTA & GGG & A & \\
\hline \multirow[t]{3}{*}{ TA } & GGG & TTA & GGG & TTA & GGG & TTA & GGG & & HT1 \\
\hline & & & & & & TA & GGG & $\mathrm{T}$ & $\mathrm{TAG}_{3} \mathrm{~T}$ \\
\hline & & & & UAG & GGG & UUA & GGG & $\mathrm{U}$ & RNA \\
\hline
\end{tabular}




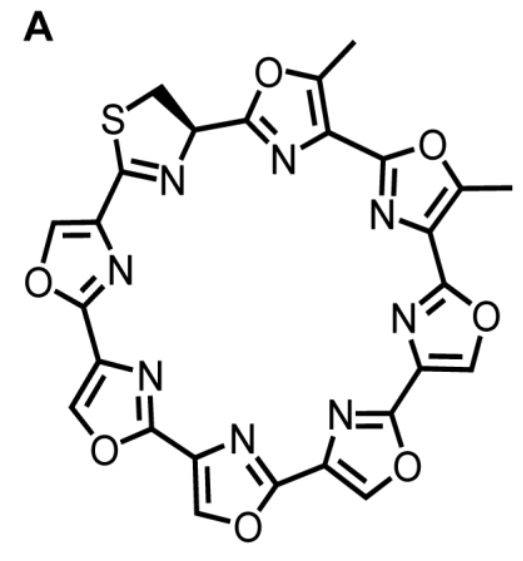

Telomestatin

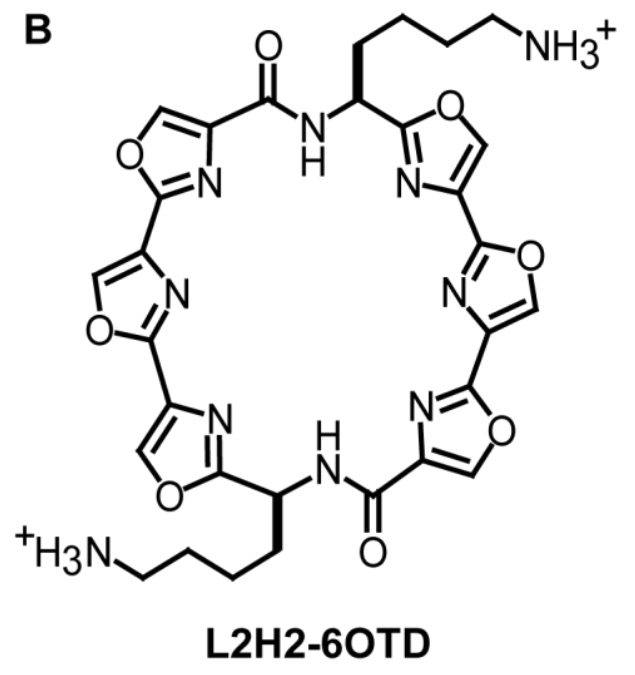

Figure S1. Chemical structure of (A) telomestatin and (B) L2H2-6OTD. 


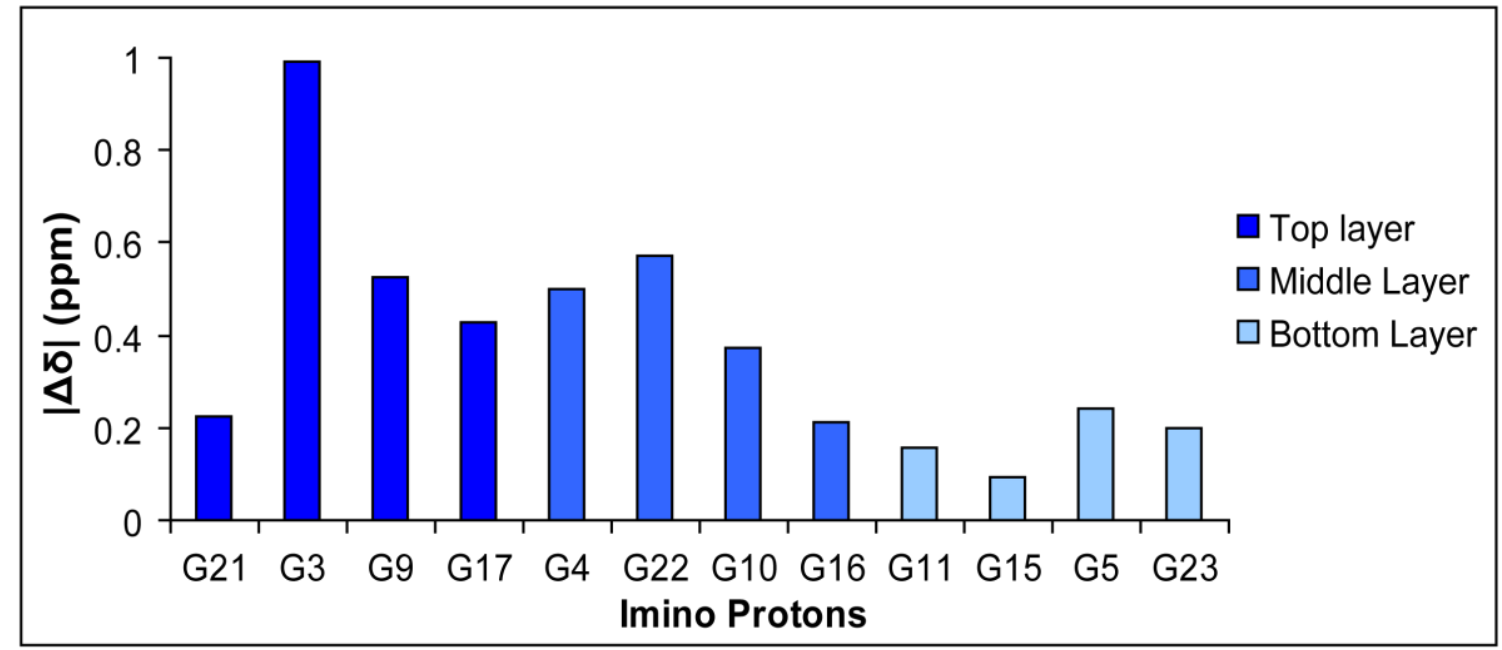

Figure S2. Diagram showing the change in the chemical shift of each imino (H1) proton. 
A

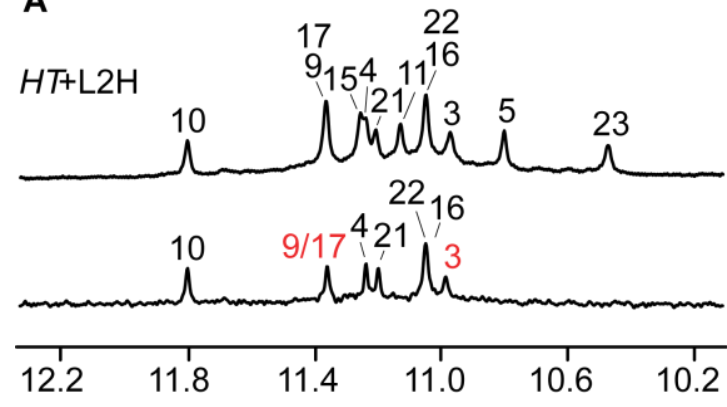

B

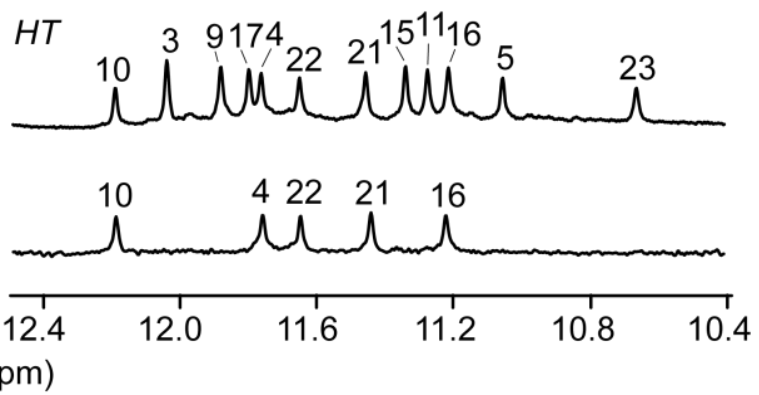

Figure S3. Solvent exchange experiments at $25^{\circ} \mathrm{C}$ of (A) the $H T$-L2H complex and (B) free $H T$. Top spectra are imino proton spectra in $\mathrm{H}_{2} \mathrm{O}$, while bottom spectra were recorded after dissolving the sample in $\mathrm{D}_{2} \mathrm{O}$ solution for 1 hour. Imino protons were numbered with the residue numbers. Imino protons that were more protected in the $H T$ - $\mathbf{L} \mathbf{2 H}$ complex are highlighted in red. 


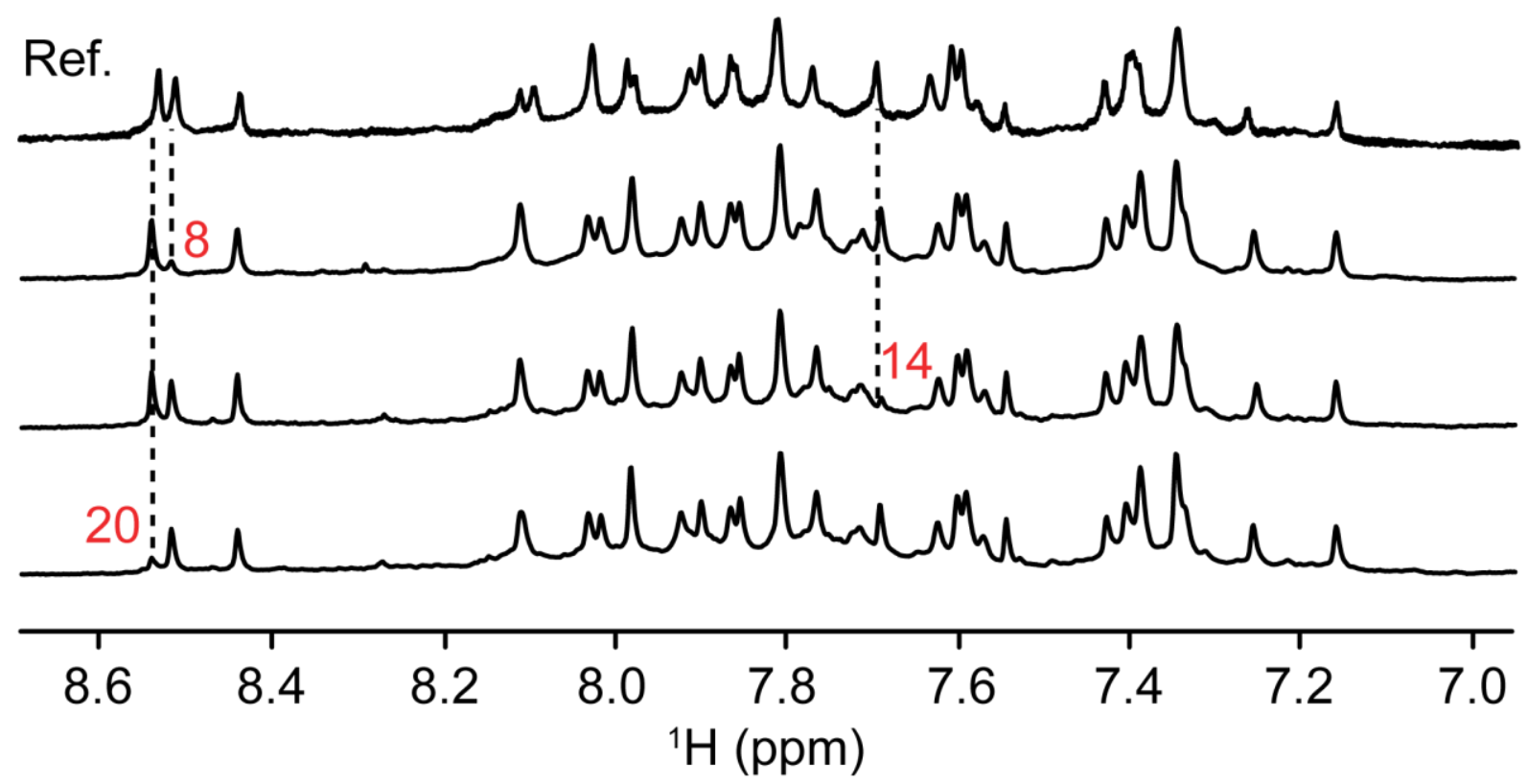

Figure S4. NMR spectra of the $H T$ - $\mathbf{L} 2 \mathbf{H}$ complex with specific deuterium-labeled guanine bases at $25^{\circ} \mathrm{C}$ in a buffer solution containing $70 \mathrm{mM} \mathrm{KCl}, 20 \mathrm{mM} \mathrm{KPi}, 10 \% \mathrm{D}_{2} \mathrm{O}, \mathrm{pH}$ 7.0. Deuterium-labeled guanine bases are indicated with residue numbers in red. 


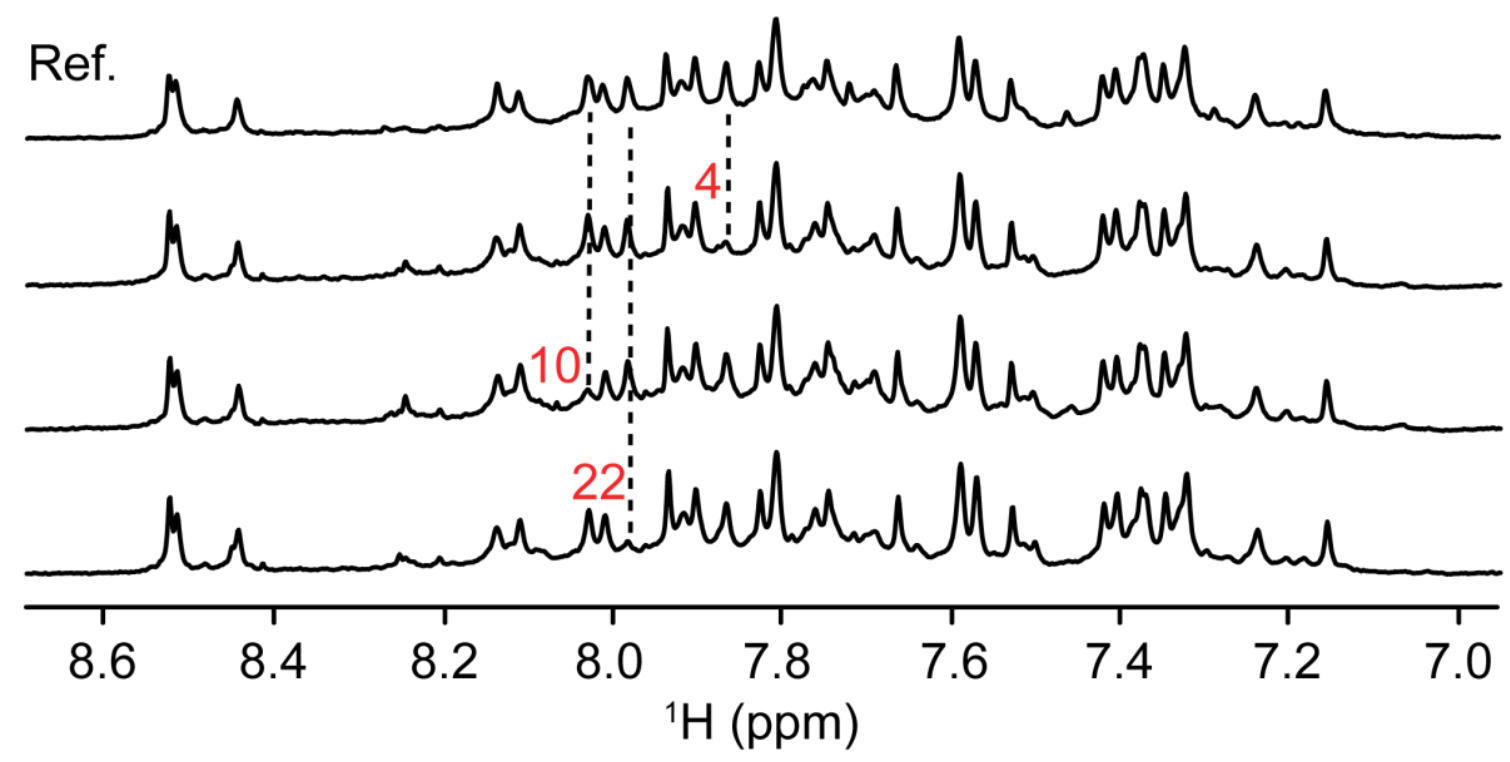

Figure S5. NMR spectra of the $H T-\mathbf{L 2 H}$ complex with specific deuterium-labeled adenine bases at $25^{\circ} \mathrm{C}$ in a buffer solution containing $70 \mathrm{mM} \mathrm{KCl}, 20 \mathrm{mM} \mathrm{KPi}, 10 \% \mathrm{D}_{2} \mathrm{O}, \mathrm{pH}$ 7.0. Deuterium-labeled adenine bases are indicated with residue numbers in red. 
A

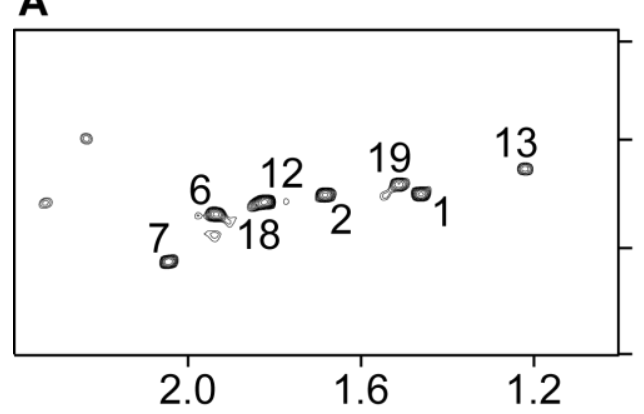

C

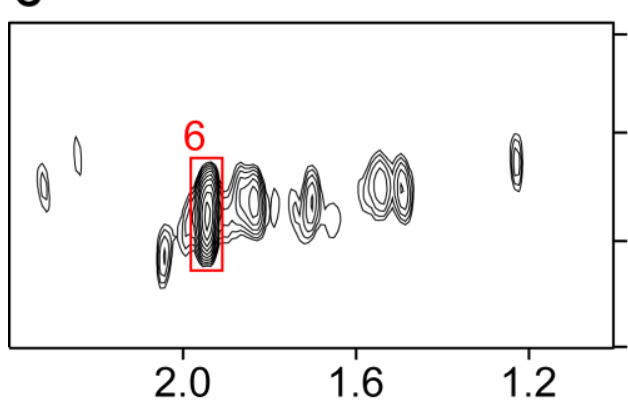

E

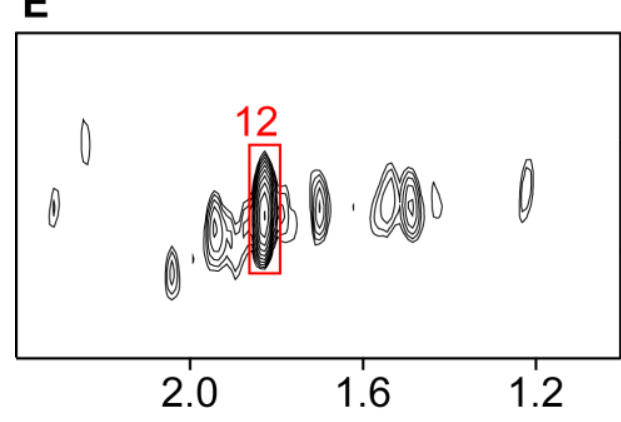

10.0

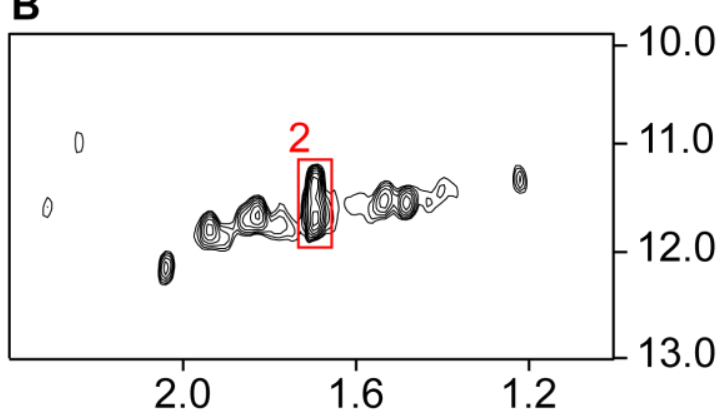

D
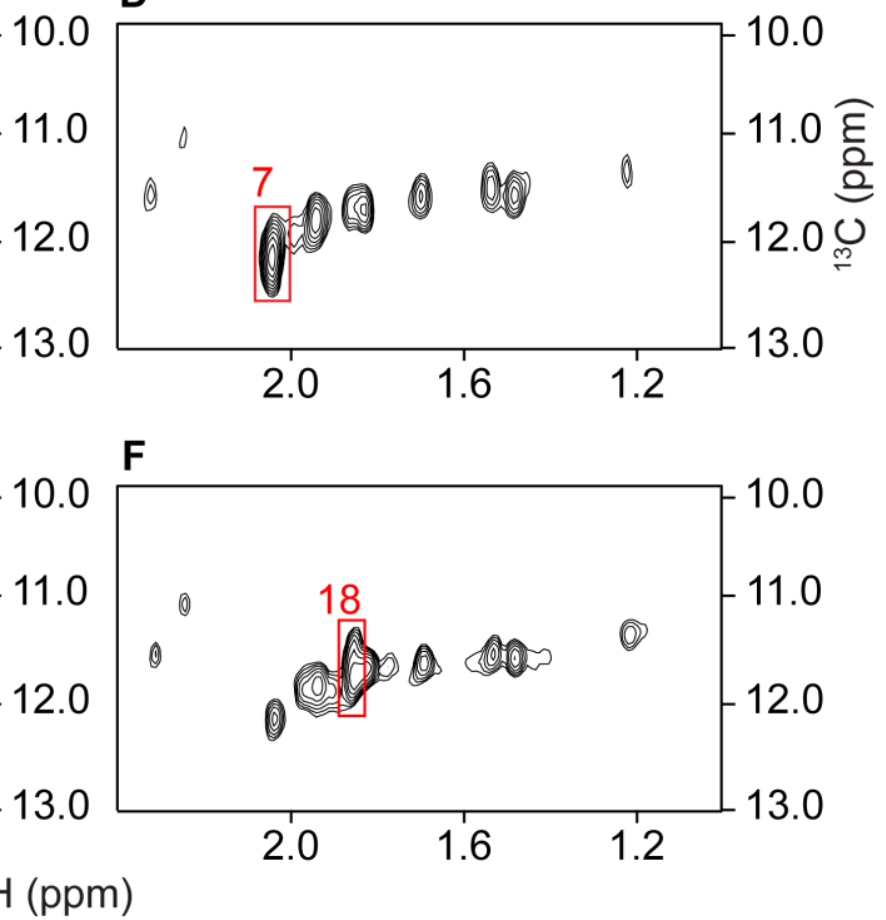

Figure S6. The methyl region of the HSQC spectrum of the HT-L2H complex. Experiments were performed using DNA containing site specific ${ }^{13} \mathrm{C}$-labeled thymine bases. (A) Unlabeled $H T$-L2H complex (reference). (B) T2-labeled $H T$-L2H complex. (C) T6-labeled $H T$-L2H complex. (D) T7-labeled $H T$-L2H complex. (E) T12-labeled HT-L2H complex. (F) T18-labeled HT-L2H complex. Labeled thymine bases are framed in red and indicated with their corresponding residue number. 

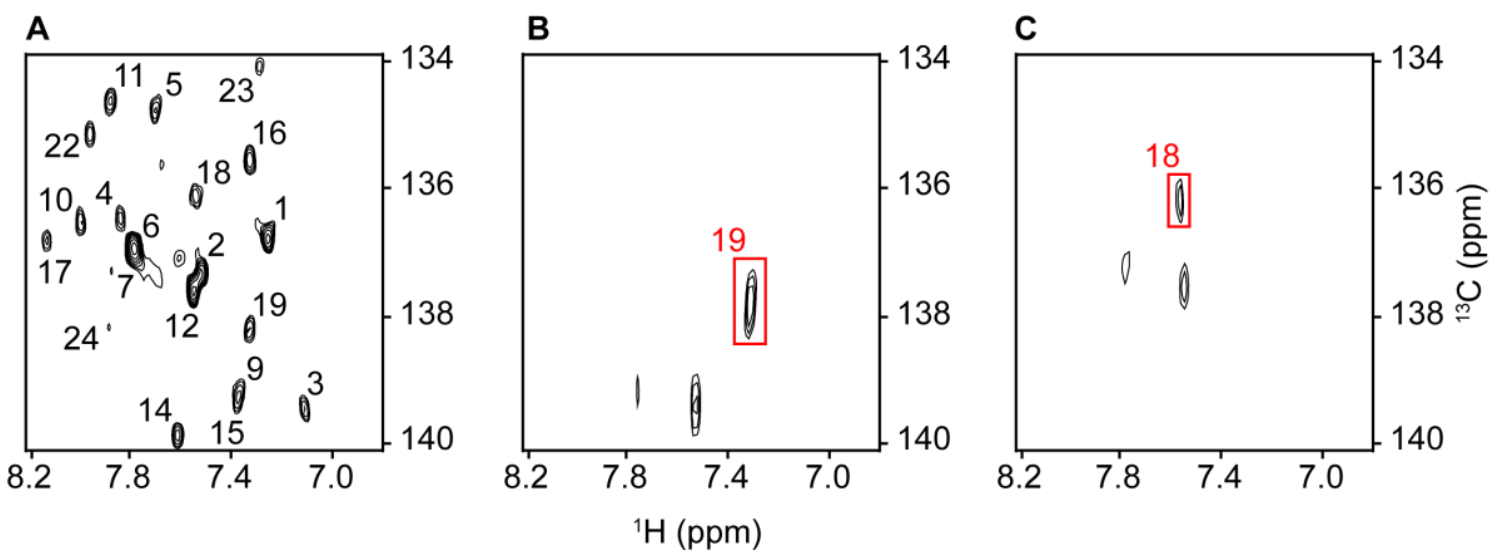

Figure S7. The aromatic region of the HSQC spectrum of the HT-L2H complex. Experiments were performed with DNA containing site specific ${ }^{13} \mathrm{C}$-labeled thymine bases. A) Unlabeled $H T$-L2H complex (reference). (B) T19-labeled $H T$-L2H complex. (C) T18-labeled $H T$-L2H complex. Labeled thymine bases are framed in red and indicated with their corresponding residue number. 


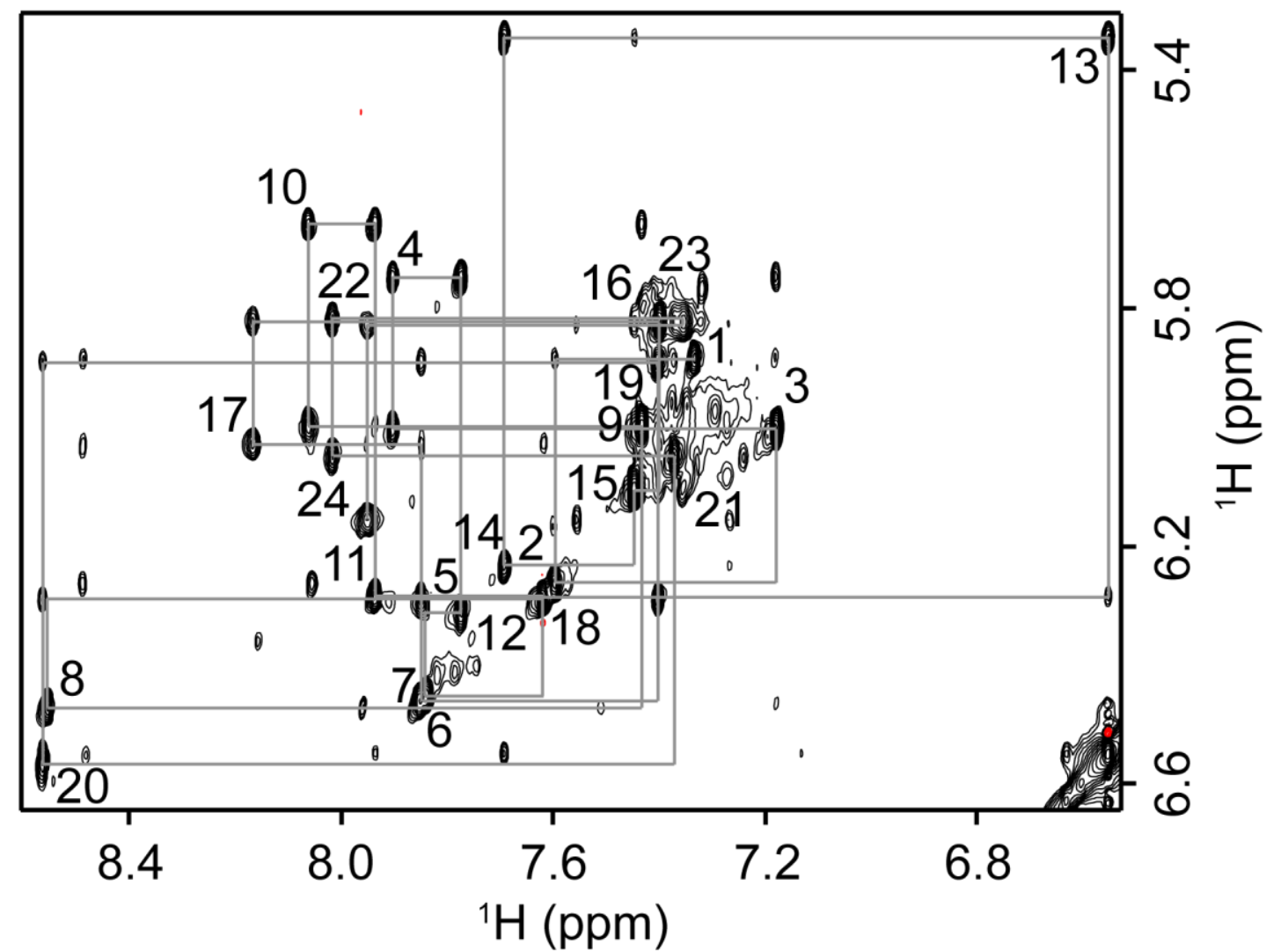

Figure S8. NOESY spectrum (mixing time, $500 \mathrm{~ms}$ ) of the $H T$-L2H complex at a [DNA]:[ligand] ratio of $1: 1$ at $25^{\circ} \mathrm{C}$. $\mathrm{H} 8 / \mathrm{H} 6$ to $\mathrm{H} 1^{\prime}$ DNA intra-residue cross-peaks are labeled with residue numbers, with the connectivity traced from T1 to G24. 


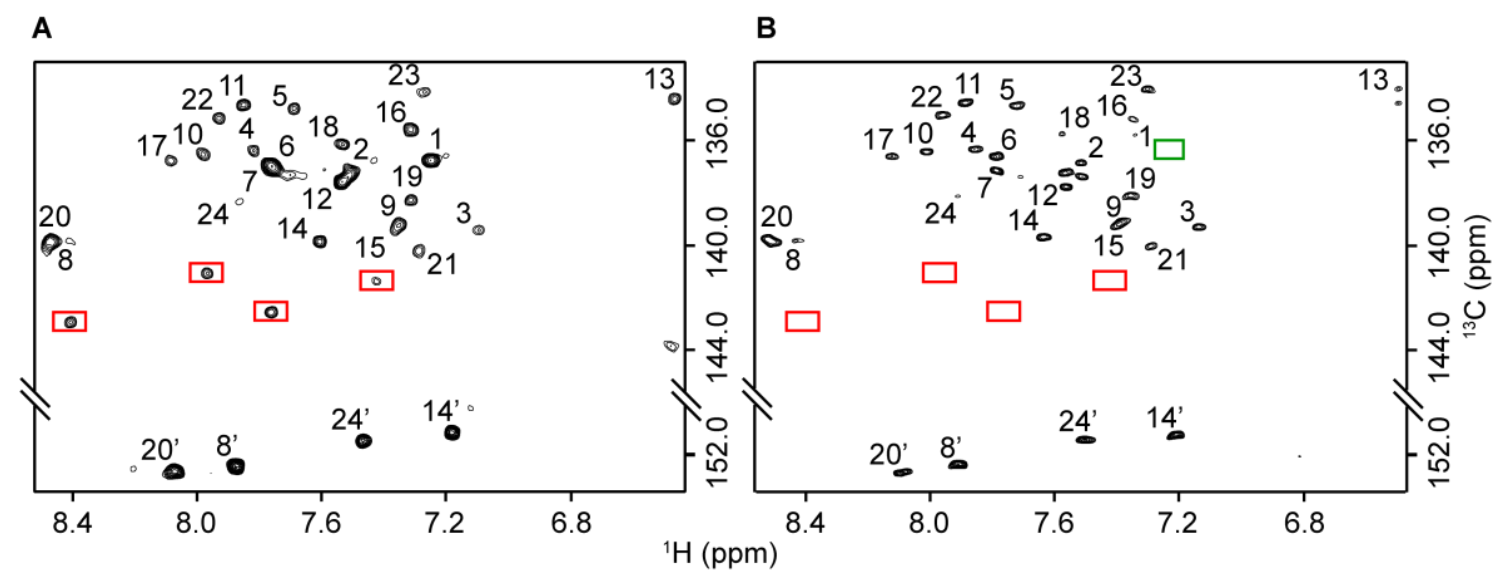

Figure S9. Aromatic region of the $\left\{{ }^{13} \mathrm{C}-{ }^{1} \mathrm{H}\right\}$ HSQC spectra of the $H T$-L2H complex at $25^{\circ} \mathrm{C}$. (A) Both DNA and ligand are unlabeled. (B) DNA is ${ }^{13} \mathrm{C}$-labeled, while ligand is not labeled. Peaks belonging to the ligands are framed in red, while peaks $(\mathrm{H} 8, \mathrm{H} 6, \mathrm{H} 2)$ belonging to $H T$ are labeled with the respective residue numbers. First residue (unlabeled T1) of the ${ }^{13} \mathrm{C}$-labeled $H T$ is framed in green. 
A

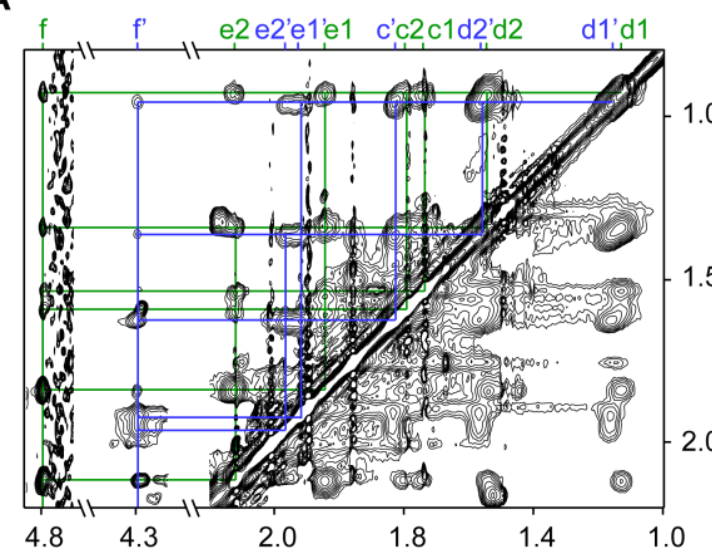

B

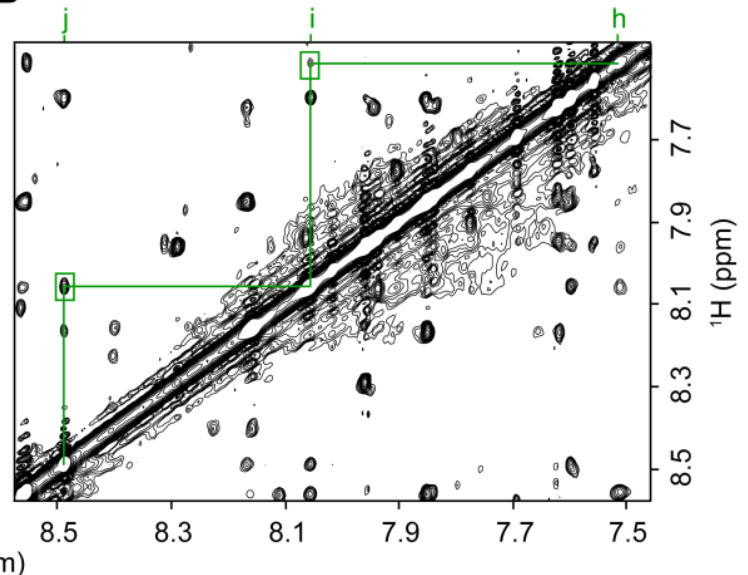

Figure S10. NOESY spectrum (mixing time, $500 \mathrm{~ms}$ ). (A) Assignment of the intramolecular cross-peaks of the alkyl chains of L2H. (B) Assignment of the intramolecular cross-peaks between the aromatic protons of L2H. 


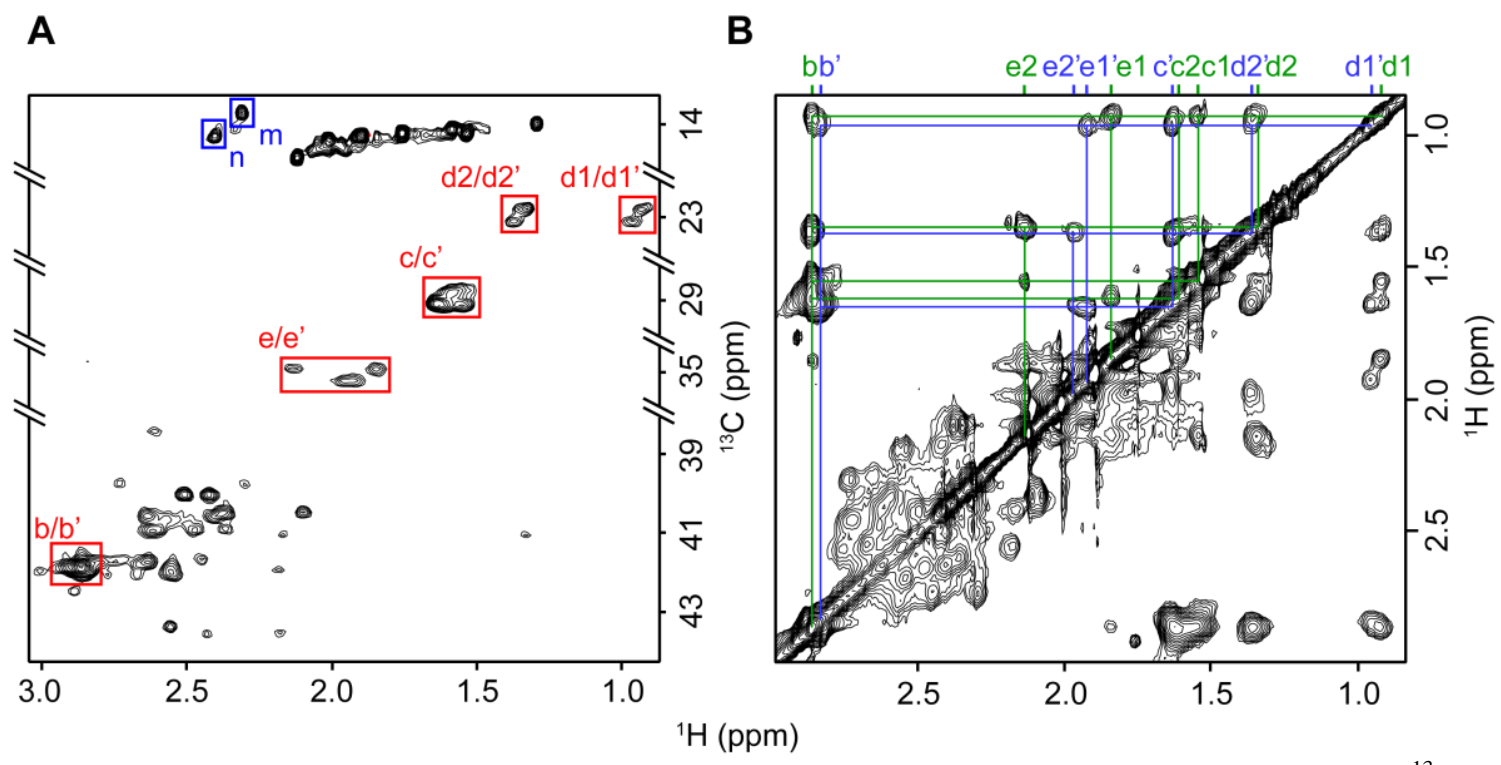

Figure S11. 2D NMR spectra for the identification of intramolecular signals arising from $\mathbf{L 2 H}$. (A) ${ }^{13} \mathrm{C}$ HSQC spectrum of the $H T$-L2H complex. Signals arising from the drug are highlighted and labeled in blue (methyl protons) and red (side chain alkyl protons). (B) TOCSY spectrum of the $H T$-L2H complex in the alkyl region. Connectivity between the protons in the two alkyl side chains are traced and indicated in green and blue respectively. 


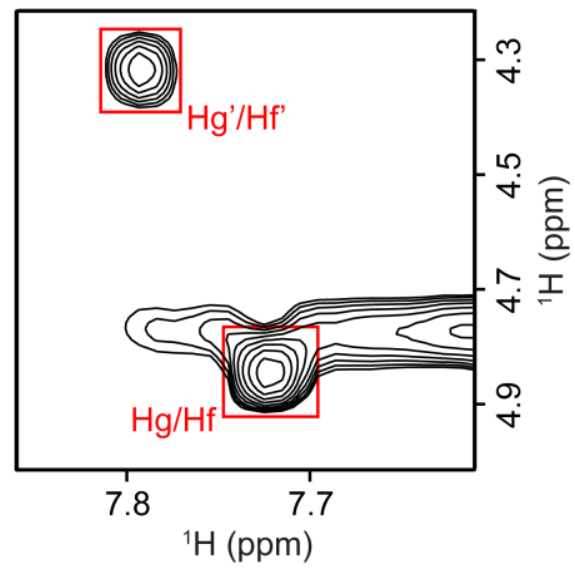

Figure S12. Identification of amide protons $\left(\mathrm{Hg} / \mathrm{Hg}^{\prime}\right)$ and alkyl protons $\left(\mathrm{Hf} / \mathrm{Hf} f^{\prime}\right)$ belonging to $\mathbf{L 2 H}$.

TOCSY spectrum showing the intramolecular cross-peaks between the amide protons ( $\mathrm{Hg} / \mathrm{Hg}$ ') and alkyl proton (Hf/Hf') of $\mathbf{L 2 H}$. Intramolecular cross-peaks between the amide protons ( $\mathrm{Hg} / \mathrm{Hg}$ ') and alkyl proton (Hf/Hf') of $\mathbf{L 2 H}$ are framed and labeled in red. 
A

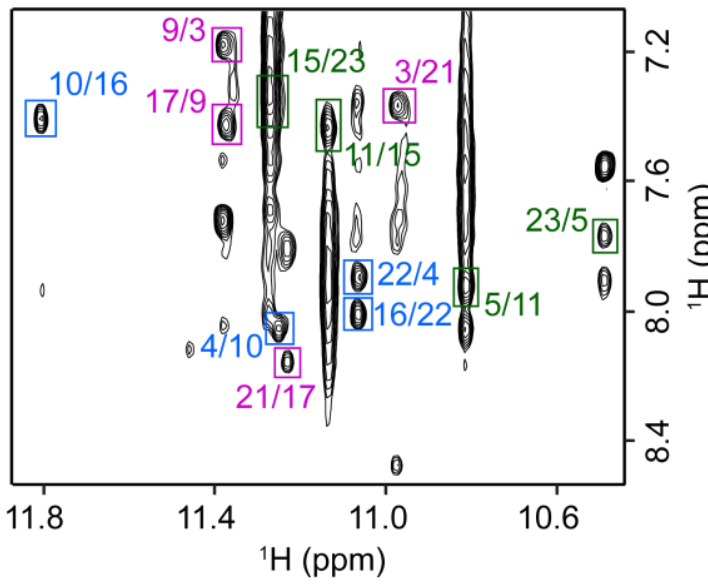

B
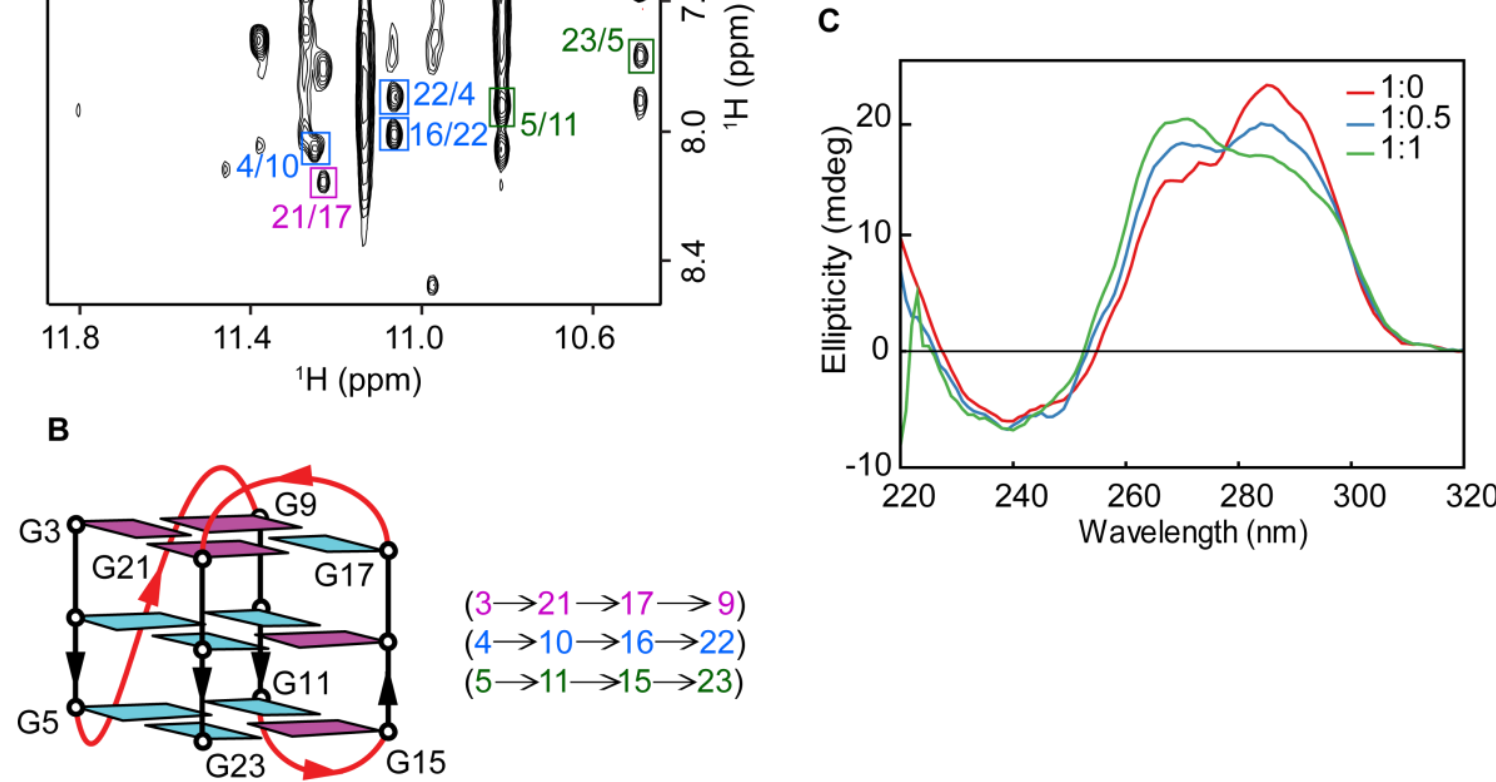

Figure S13. (A) NOESY spectrum (mixing time, $300 \mathrm{~ms}$ ) showing connectivity pattern between guanine $\mathrm{H} 1-\mathrm{H} 8$ protons. Cross peaks between the imino $\mathrm{H} 1$ protons and aromatic $\mathrm{H} 8$ protons are framed and labeled with the residue number of imino protons in the first position and that of $\mathrm{H} 8$ protons in the second position. The first, second and third G-tetrad layer are colored in magenta, cyan and forest green, respectively. (B) Folding topology of bound $H T$. (C) CD titration of $H T(5 \mu \mathrm{M})$ with increasing concentrations of $\mathbf{L 2 H}(0-15 \mu \mathrm{M})$ at $25^{\circ} \mathrm{C}$ in $70 \mathrm{mM} \mathrm{KCl}$ and $20 \mathrm{mM} \mathrm{KPi}, \mathrm{pH}$ 7. Ratio of $H T$ to $\mathbf{L 2 H}$ is indicated on the right side of the spectrum. 

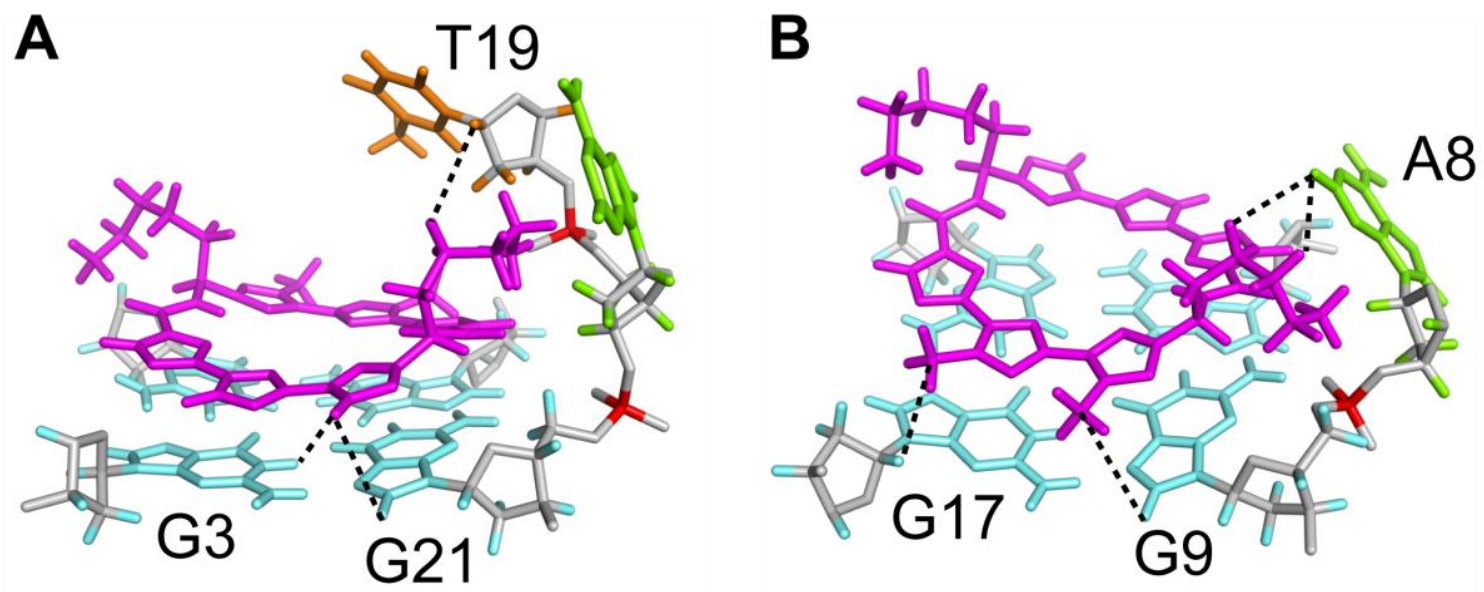

Figure S14. Stick representation of $H T$-L2H complex with critical distant restraints between $H T$ and $\mathbf{L 2 H}$ indicated with black dotted lines. (A) Side view highlighting the close proximity of one side chain of $\mathbf{L} \mathbf{2 H}$ to the H1' proton of T19 and the aromatic protons of $\mathbf{L} \mathbf{2 H}$ to the protons on the top G-tetrad. (B) Side view highlighting the close proximity of the opposite side chain of $\mathbf{L 2 H}$ to the $\mathrm{H} 2$ proton of $\mathrm{A} 8$ and the methyl groups of $\mathbf{L 2 H}$ to protons on the top G-tetrad. $\mathbf{L 2 H}$ is highlighted in magenta; Guanine residues are colored in cyan; Adenine residues are colored in green, Thymine resides are colored in orange; Backbone is colored in grey; Phosphate groups are highlighted in red. 

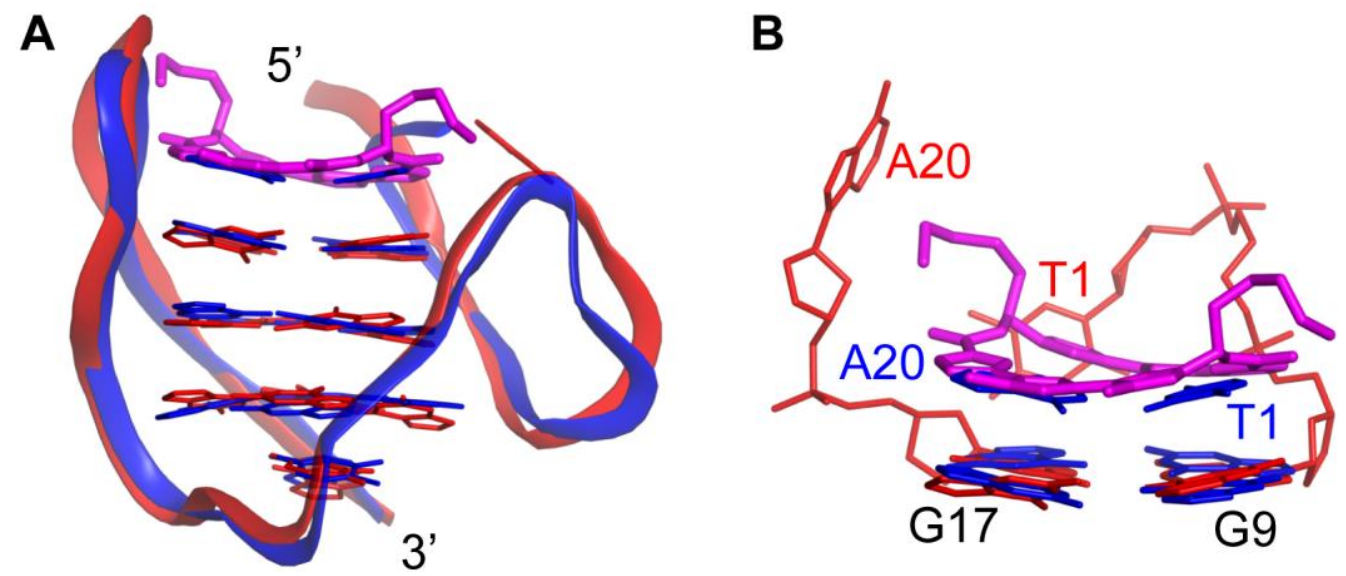

Figure S15. (A) Ribbon representation showing the retention of the folding topology by superimposing the free $H T$ and the $H T$-L2H complex. (B) Stick representation showing the displacement of the A20•T1 base pair in the free $H T$ by $\mathbf{L 2 H}$ by superimposing the structures of the free $H T$ and the $H T$ - $\mathbf{L} \mathbf{2 H}$ complex. The bound $H T$ is colored in red, $\mathbf{L} \mathbf{2 H}$ is colored in magenta and the free $H T$ is colored in blue. The bases are labeled with their respective residue numbers. 
A

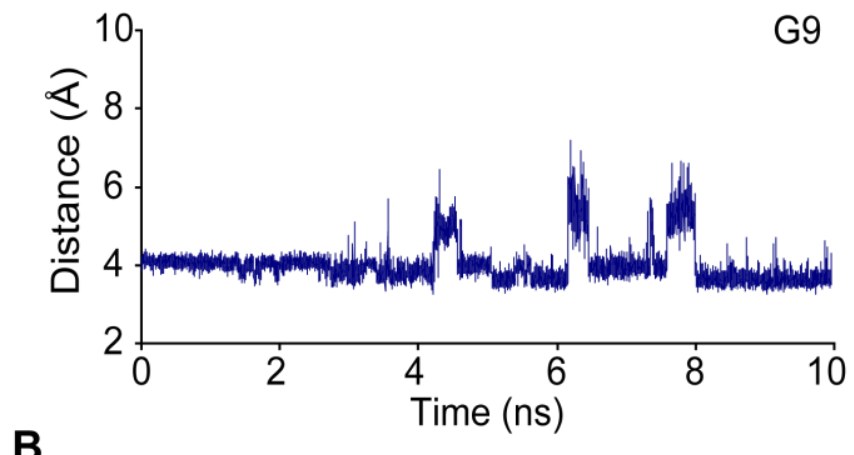

B
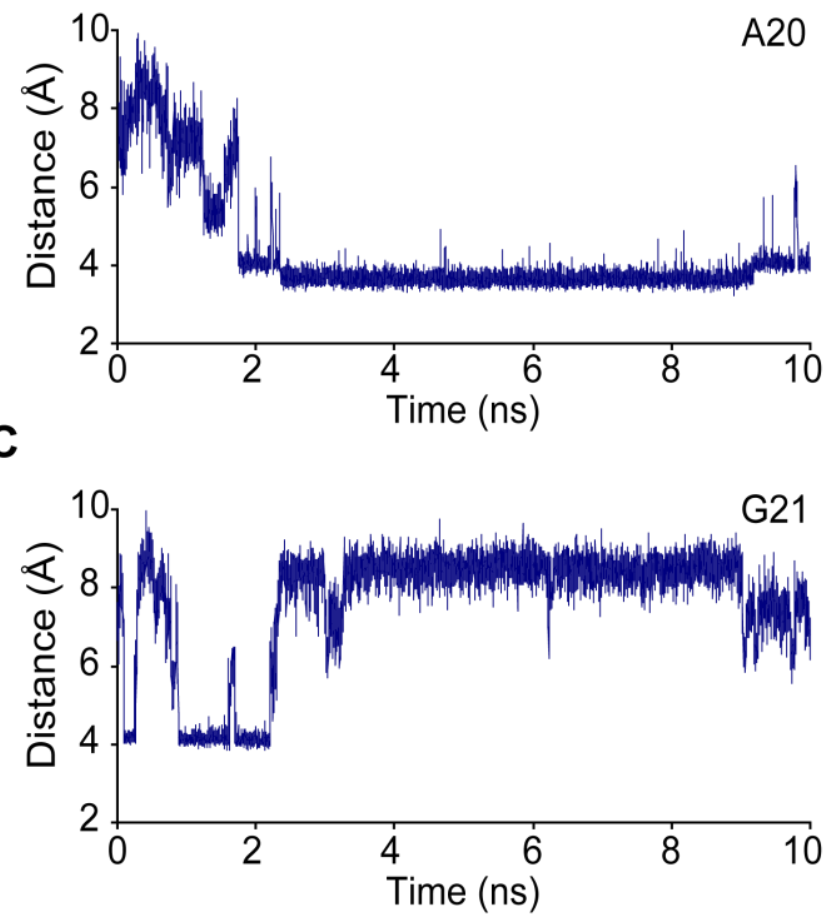

Figure S16. Graph showing the distance between the phosphorous atom of the respective residue with the nearest amine side chain of $\mathbf{L 2 H}$ over the 10-ns molecular dynamics simulation. (A) G9. (B) A20. (C) G21. 
A

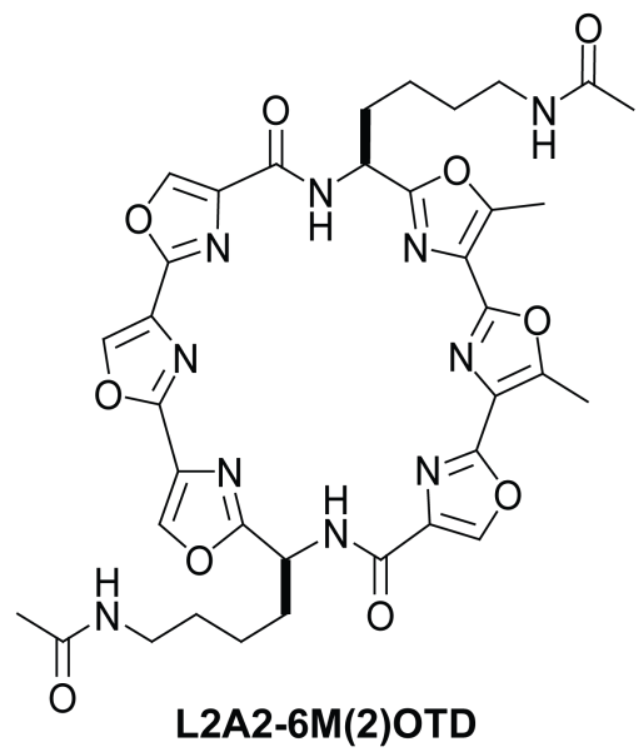

C

$H T+\mathrm{L} 2 \mathrm{~A}$
B<smiles>C[R16](C)(C)O[O+]=O</smiles>

D

\section{$\mathrm{HT}+\mathrm{L} 2 \mathrm{H}$}

[DNA]:[Ligand]

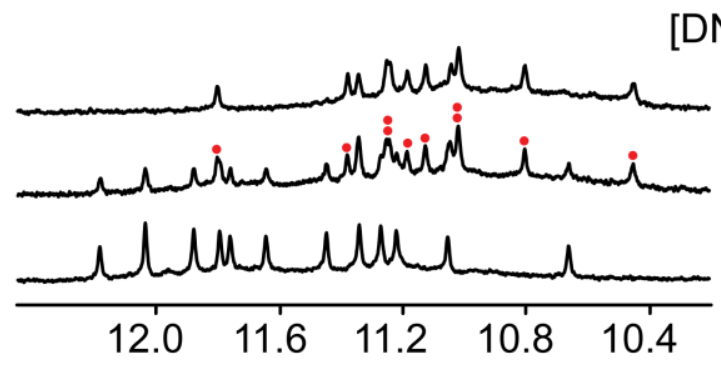
$1: 2$ $1: 1$

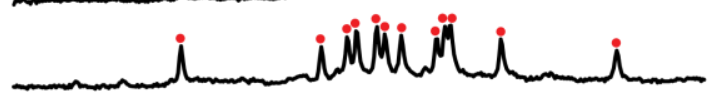
$1: 0$ ${ }^{1} \mathrm{H}$ (ppm)

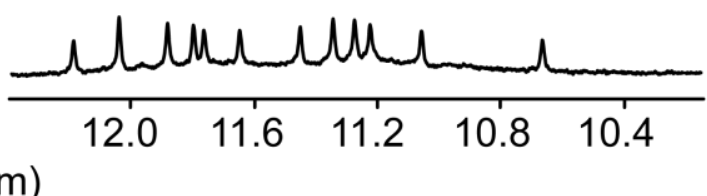

Figure S17. (A) Structure of L2A2-6M(2)OTD (L2A). (B) Structure of L2H2-6M(2)OTD (L2H). Titration of $H T$ with increasing concentrations of telomestatin derivatives. (C) L2A. (D) L2H. The [DNA]:[ligand] ratio is indicated at the centre of the two spectra. First complex formation is indicated with red dots. Second complex formation is indicated with blue dots. 


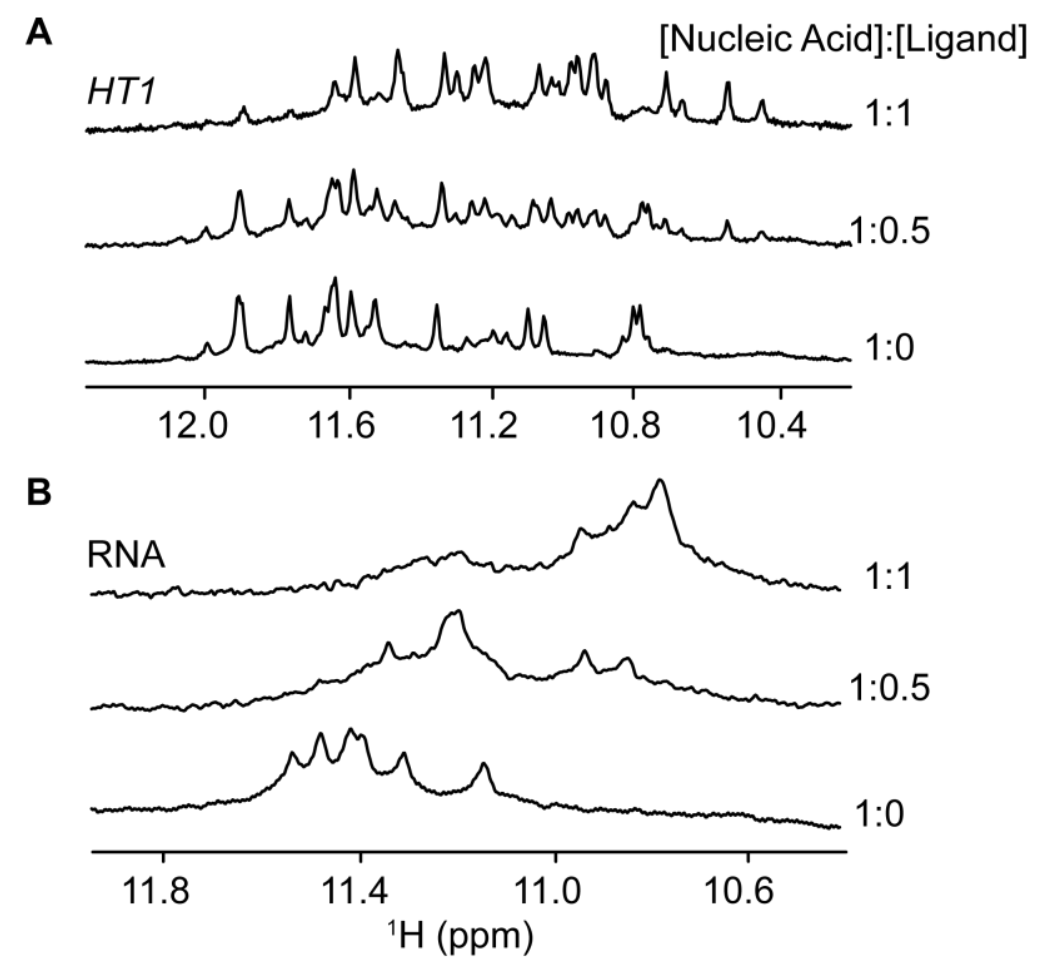

Figure S18. Titration of G-quadruplex with increasing concentrations of $\mathbf{L 2 H}$ on different G-quadruplex folds. (A) $H T 1,(3+1)$ G-quadruplex. (B) RNA, parallel G-quadruplex. The [Nucleic Acid]:[Ligand] ratio is indicated at the side of the spectra. 


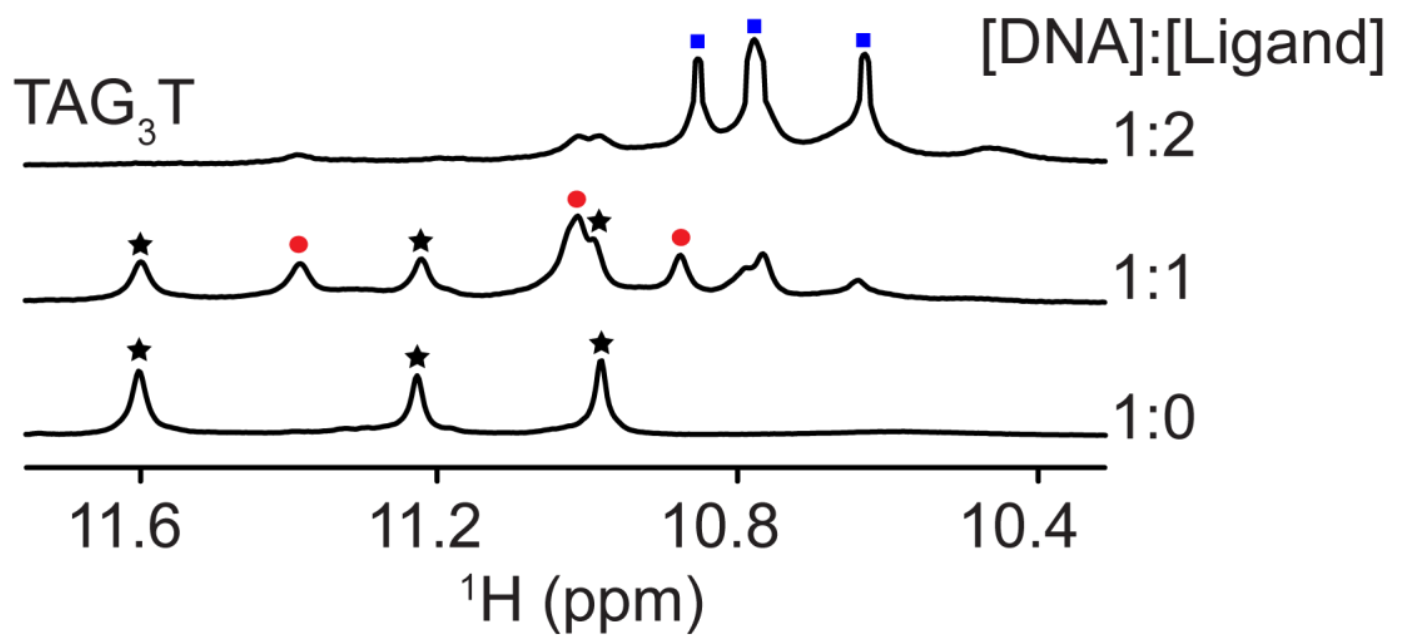

Figure S19. Titration of $\mathbf{L 2 H}$ to $\mathrm{TAG}_{3} \mathrm{~T}$ showing the formation of a second set of peaks when two equivalents of ligand are added to the DNA. The [DNA]:[ligand] ratio is indicated at the side of the spectra. Free DNA is indicated with black stars. First complex formation is indicated with red dots. Second complex formation is indicated with blue squares. 